\title{
Well-differentiated thyroid carcinoma invading the larynx and trachea
}

\author{
Melissa Laus*, Domenico Crescenzi, Alessandro De Stefano, Adelchi Croce \\ ENT Department, University “G. D’Annunzio” of Chieti-Pescara, Hospital "SS. Annunziata”, Via dei Vestini, 66100 Chieti, Italy
}

Email address:

melissa.laus@hotmail.it (M. Laus)

\section{To cite this article:}

Melissa Laus, Domenico Crescenzi, Alessandro De Stefano, Adelchi Croce. Well-Differentiated Thyroid Carcinoma Invading the Larynx and Trachea. Clinical Medicine Research. Vol. 2, No. 6, 2013, pp. 148-153. doi: 10.11648/j.cmr.20130206.16

\begin{abstract}
Larynx and trachea invasion by thyroid cancer is an uncommon but difficult problem. There is no consensus on indication for the extent of surgery, particularly when there is a requirement for airway reconstruction. In general, the surgeon must decide between a complete ablation of the tumor at the cost of large-mutilation and a less radical dissection that leaves residual tumor to be treated with radiation therapy and additional radio-iodine.
\end{abstract}

Keywords: Papillary Carcinoma, Larynx, Trachea, Total Laryngectomy

\section{Introduction}

Thyroid cancer is one of the most common endocrine malignancies, second only to ovarian cancer $[1,2]$. Carcinomas of the thyroid can be classified histologically into four types: papillary, follicular, medullary and anaplastic. These cancers may further be divided into two main groups: those of low grade and those of high grade malignancy.

Low grade malignant tumours include papillary, follicular and mixed papillary-follicular tumours while medullary and anaplastic tumours are high grade malignancies [2- 5] (Table I).

Table I: Histological classification of thyroid tumors.

\begin{tabular}{|c|c|c|}
\hline $\begin{array}{l}\text { Thyroid } \\
\text { Carcinomas }\end{array}$ & $\begin{array}{l}\text { Low Grade } \\
\text { Malignant }\end{array}$ & $\begin{array}{l}\text { High Grade } \\
\text { Malignancies }\end{array}$ \\
\hline & $\begin{array}{ll}- & \text { Papillary } \\
\text { - } & \text { Follicular } \\
\text { - } & \text { Mixed Papilary-Follicular Tumours }\end{array}$ & $\begin{array}{ll}- & \text { Medullary } \\
- & \text { Anaplastic }\end{array}$ \\
\hline
\end{tabular}

It is known that $80-90 \%$ of all thyroid tumors are of low grade malignancy with only $10-20 \%$ being highly malignant. In patients with low grade malignancies life expectancy is quite long, depending on the extent of spread of the tumour; long survival in the presence of lung or bone metastases is not uncommon. In contrast the high grade malignancies show rapid growth and spread, with death being almost inevitable within 2 years $[5,6]$. Adverse prognostic factors have been well-established and include age, extra-thyroidal extension, tumor histology, primary tumor size, and distant metastasis [7, 8]. Extra-thyroidal extension has the greatest negative impact on prognosis. Invasion of the larynx and trachea by malignant tumours of the thyroid gland, either low grade or high grade, is a very difficult problem for the surgeon [3].

\section{Discussion}

Differentiated thyroid carcinoma originates from thyroid follicular cells is the most prominent malignancy of endocrine organs. There are two histological types of differentiated carcinoma, namely, papillary and follicular carcinoma. There are many studies that consider the papillary carcinoma as latent in autopsy specimens [9-16]. The prevalence of latent thyroid carcinoma is 3500 per 100,000 females, which is about 1000 times higher than that of papillary carcinoma treated clinically, 1.9-11.7 per 100,000 female (and 1.0-4.8 per 100,000 males) [16]. Furthermore, the papillary carcinoma is most frequently detected when patients are in their forties [17]. In contrast, 
there are several autopsy and clinical studies that have indicated that papillary carcinoma showed a high incidence of lymphnode metastasis and multicentricity even for papillary microcarcinoma, that is, papillary carcinoma measuring $1 \mathrm{~cm}$ or less [16, 18-27].

There are some classification systems for papillary carcinoma that were proposed in order to identify high-risk cases. The prominent one is the American Joint Cancer Committee/Union Internationale Contre le Cancer (UICC/AJCC) TNM staging system [28]. This system basically evaluates time-oriented carcinoma progression by upstaging based on tumor size, extrathyroid extension, lymph node metastasis, distant metastases, and patient age. In the 1980s and early 1990s, diagnosis and evaluation of papillary carcinoma was completely reformed. Ultrasound is standard at most institutions for the initial evaluation of thyroid disease and can be combined with fine-needle aspiration biopsy for diagnostic purposes [8, 29-31]. When extrathyroidal extension of thyroid cancer is suspected, based on the patient's history or physical examination, cross-sectional imaging with CT or MRI is essential. CT with contrast represents an ideal study for advanced surgical planning. MRI with gadolinium may be a good alternative
[8]. The extrathyroidal extension of thyroid malignancies is associated with a higher rate of distant metastases and the FDG-PET/CT scanning has been shown to be particularly useful for imaging the more aggressive ones [8, 32-33]. Additional investigations may be performed at the time of surgery, including laringoscopy/ tracheoscopy/bronchoscopy and esophagoscopy [8]. The optimal management of thyroid cancer is dependent on the assessment of the malignant potential of the individual tumor at presentation. The prognostic factors in thyroid cancer are very well defined. Patient age, tumor grade, tumor size and distant metastasis. The most important prognostic factor from a surgical standpoint, however, is extrathyroidal extension. Patients with extrathyroidal extension have an increased incidence of local recurrence, regional spread and distant metastases [34]. Generally, a well-differentiated thyroid cancer as the papillary carcinoma shows an indolent behaviour. Rarely, this cancer show a very rapid growth with an adverse prognosis. A contemporary review from Honings et al reported a revision of 20 studies to a total of 10,251 patients with thyroid cancer, of which $595(5.8 \%)$ with invasion of the airways [35-56] (Table modified II).

Table II: Occurrence of laryngotracheal invasion by thyroid carcinoma (Studies >50 cases).

\begin{tabular}{|c|c|c|c|c|c|c|}
\hline First Author & Year & $\begin{array}{l}\text { Period, } \\
\text { Yr }\end{array}$ & $\begin{array}{l}\text { No. Of Thyroid } \\
\text { Carcinomas }\end{array}$ & $\begin{array}{l}\text { Airy } \\
\text { No. }\end{array}$ & $\%$ & Well Differentated, \% \\
\hline \multicolumn{7}{|c|}{ All Thyroid Carcinomas } \\
\hline Schindel J & 1971 & 15 & 225 & 10 & 4.4 & Ns \\
\hline Bresux Gp & 1980 & 10 & 210 & 44 & 21.0 & 72.2 \\
\hline Segal K & 1984 & 25 & 500 & 29 & 5.8 & 65.5 \\
\hline Tsumori T & 1985 & 24 & 180 & 28 & 15.6 & Ns \\
\hline Mccarty Tm & 1997 & 44 & 597 & 40 & 6.7 & 85 \\
\hline Koike E & 2001 & 0.5 & 171 & 16 & 9.4 & 93.8 \\
\hline Sywak M & 2003 & 2 & 97 & 7 & 7.2 & 100 \\
\hline Tsai Yf & 2005 & 15 & 532 & 43 & 8.1 & 93.0 \\
\hline Randolph Gw & 2006 & - & 135 & 21 & 15.6 & Ns \\
\hline \multicolumn{7}{|c|}{ Well-Differentiated Thyroid Carcinomas } \\
\hline Fridman M & 1982 & 30 & 190 & 13 & 6.8 & 100 \\
\hline $\begin{array}{l}\text { Mcconahey } \\
\text { Wm }\end{array}$ & 1986 & 25 & 859 & 85 & 9.9 & 100 \\
\hline Nishida T & 1997 & 25 & 301 & 69 & 22.9 & 100 \\
\hline Hu A & 2007 & 38 & 576 & 13 & 2.3 & 100 \\
\hline
\end{tabular}

*The cases reported by Lawson are not included in the totals.

$\mathrm{NS}=$ not stated.

This study may be the best general estimate of laryngotracheal tumor adherence or invasion among all patients presenting for surgical resection. We can therefore say that surgical resection is the primary treatment for patients with locally aggressive thyroid cancer; extrathyroidal extension and local invasion are important for a proper surgical excision of all gross disease and the need for adjuvant therapy, such as external beam radiation therapy and radioactive iodine [34]. The principles of surgical management of locally advanced thyroid cancer are these: removal of all gross tumor, preservation of functioning structures, preservation of vital structures and use of adjuvant therapies. There are many controversies in the management of differentiated thyroid cancer. Total thyroidectomy is recommended in all prominent guidelines used in Western countries. The benefits of total thyroidectomy are: 1) the serum thyroglobulin level can be used as a marcker of carcinoma recurrence; 2) radioiodine ablation therapy or whole body scan can be performed immediately when carcinoma recurrence is suspected; 3) 
there is no risk of recurrence to the remnant thyroid. Its demerits are: 1) chronic administration of thyroid hormone becomes absolutely necessary after surgery; 2) persistent hypoparathyroidism may occur; 3 ) the incidence of recurrent nerve paralysis may increase. Thyroidectomy is more frequently performed for patients with papillary carcinoma having clinicopathological parameters predicting a worse prognosis, such as clinically apparent lateral node metastasis (N1b) and massive extrathyroid extension (pT4), regardless of tumor size or whether the tumor is solitary or multiple [16]. Laryngeal involvement is relatively rare, occurring in $12 \%$ of patients with locally invasive thyroid cancer [57] and specific recommendations must be tailored for each individual case. The surgical options are essentially: partial laryngectomy, and total laryngectomy. Thyroid cancer invading the laryngeal cartilage without intraluminal involvement can be treated by shaving the tumor from the underlying cartilage. If the tumor extends intraluminally, however, an open procedure will be necessary. If only one side has been invaded, the tumor may be amenable to a partial laryngectomy. Early cricoid cartilage invasion can be treated by shave excision. Subglottic invasion via direct cricoid cartilage invasion or through the cricothyroid membrane may require a total laryngectomy [34, 58]. Friedman noted higher recurrence rates and worse survival in patients with incomplete resection when compared with those undergoing radical resection [59]. Others have noted success with partial laryngeal surgery for locally invasive thyroid cancer [60]. Indications for total laryngectomy include airway obstruction, luminal hemorrhage, intraluminal invasion, or lack of larynx function [61-64]. This approach has demonstrated good local control for extensive larynx invasion [65] and is less morbid than organ-preserving or palliative therapies [64]. Tracheal invasion has been more extensively studied and characterized due to its greater frequency relative to laryngeal involvement [66]. In fact, tracheal invasion occurs in one third of cases of locally invasive thyroid cancer. In patients with superficial tumor adherence to the trachea, one should consider preservation procedures. In patients with more aggressive variants, complete surgical resection is considered optimal therapy. There are three compartments of regional lymphnodes in thyroid carcinoma: central, lateral and mediastinal compartments. Lymphnode dissection has not been actively recommended and only a guideline from American Thyroid Association has recommended routine dissection of the central compartment. One study recommended prophylactic mediastinal node dissection, but in most departiments, the mediastinal compartiment is not dissected unless metastasis is highly suspected on imaging studies. Endocrine surgeons in Japan tend to routinely dissect the central compartment during surgery for papillary carcinoma [67-69]. Re-operation for recurrence to the central node may include severe complications such as recurrent laryngeal nerve injury and persistent hypoparathyroidism [70-72]. There are no guidelines recommending lateral node dissection unless clinically apparent node metastasis has been detected in the compartment. None of the Western guidelines recommended prophylactic dissection of the lateral compartment (modified radical neck dissection) and previous studies showed negative results [73-75], although some departments recommended it [76-78]. The increased surgical duration and blood loss, wound extension, the possibility of injury to other organs such as the thoracic duct, and increased patient complaints such as neck discomfort can be listed as the demerits of prophylactic dissection of the lateral compartment. The range to which patients can tolerate reoperation is actually an important point to consider in the application of prophylactic dissection of the lateral compartment. The application of prophylactic dissection of the lateral compartment remains an open question. A controversial element of remaining thyroid tissue treatment is radioactive iodine ablation. After a partial or subtotal thyroidectomy, radioactive iodine can be used for diagnosis and treatment of reimaining thyroid tissue or metastatic tissue. Radioactive iodine ablation has been shown to reduce recurrences [79] and some believe it may even improve survival in selected patients [80-81]. While gross disease is best treated surgically, radioactive iodine is the treatment of choice in patients who are suspected of having persistent and/or occult disease. Radioactive iodine is a vital adjuvant treatment used not only to ablate the thyroid remnant, but also to treat patients deemed to be at high risk of recurrence after pathologic review (local invasion, positive margins or aggressive histological subtype).

\section{Conclusion}

There is no consensus regarding the management of patients with thyroid malignancies invading larynx and trachea. The surgeon must decide between a complete ablation of tumour at the cost of extensive mutilation and a less radical dissection which leaves residual tumour to be treated by complementary radiotherapy and radio-iodine.

\section{Competing Interests}

The authors declare that they have no competing interests.

\section{Author's Contributions}

All authors critically revised the manuscript and have approved the final manuscript.

\section{References}

[1] Kebebew E, Clark OH, "Differentiated thyroid cancer: "complete" rational approach", World J Surg, vol. 24, pp. 942-951, 2000.

[2] Caron NR, Clark OH, "Well differentiated thyroid cancer", Scandinavian Journal of Surgery, vol. 93, pp. 261-271, 2004. 
[3] Segal K, Abraham A, Levy R, "Carcinomas of the thyroid gland invading larynx and trachea", Clin Otolaryngol vol. 9, pp. 21-25, 1984.

[4] Schlumberger M, Pacini F, "Thyroid tumors”, Nucleon, Paris, pp. 40-47, 2003.

[5] Mvouni S, Tombu S, Meurisse M, "Management of an insular thyroid carcinoma invading the larynx and trachea" B-ENT, vol. 2, pp. 17-20, 2006.

[6] Schindel J, "Surgery in malignant tumors of the thyroid gland A review of 15 years experience with 225 cases", Ann Otol Rhinol Laryngol, vol. 80, pp. 61-66, 1971.

[7] Shah JP, Loree TR, Dharker D, "Prognostic factors in differentiated carcinoma of the thyroid gland", Am J Surg, vol. 164(6), pp. 658-61, 1992.

[8] Price DL, Wong RJ, Randolph GW, "Invasive thyroid cancer: management of the trachea and esophagus", Otolaryngol Clin North Am vol. 41(6), pp. 1155-1166, 2008.

[9] Harach HR, Franssila KO, Wasenius VM, "Occult papillary carcinoma of the thyroid: A "normal" finding in Finland", Cancer vol. 56, pp. 531-538, 1985.

[10] Fukunaga FH, Yatani R, "Geographic pathology of occult thyroid carcinomas”, Cancer vol. 36, pp. 1095-1099, 1975.

[11] Samaon RJ, "Prevalence and significance of occult thyroid cancer" in: DeGroot LJ, Editor. Radiation-associated thyroid carcinoma, New York, Grune \& Stratton 1977, pp.137-153.

[12] Nishiyama RH, Ludwing GK, Thompson NW, "The prevalence of small papillary thyroid carcinomas in 100 consecutive necropsies in an American population", in: DeGroot LJ, Editor. Rsdiation-associated thyroid carcinoma, New York, Grune \& Stratton; 1977, pp.123-135.

[13] Thorvaldsson Se, Tulinius H, Bjornsson J, "Latent thyroid carcinoma in Iceland at autopsy", Pathol Res Pract, vol. 188, pp. 747-750, 1992.

[14] Lang W, Borrusch G, Bauer L, "Occult carcinomas of the thyroid”, Am J Clin Pathol, vol. 90, pp. 72-76, 1988.

[15] Yamamoto Y, Toshiharu M, Izumi K, "Occult papillary carcinoma of the thyroid", Cancer vol. 65, pp. 1173-1179, 1990.

[16] Ito Y, Miyauchi A, "Prognostic factors and therapeutic strategies for differentiated carcinomas of the thyroid" Endocrine Journal, vol. 56, pp. 177-192, 2009.

[17] Takebe K, Date M, Yamamoto Y, "The detection minimal thyroid cancer in mass screening with ultrasonography", Geka vol. 58, pp. 651-654, 1996.

[18] Iida F, Sugenoya A, Muramatsu A, "Clinical and pathologic properties of small differentiated carcinomas of thyroid gland”, World J Surg vol. 15, pp. 511-515, 1991.

[19] Hay ID, Grant CS, van Heerden JA, "Papillary thyroid microcarcinoma: A study of 535 cases observed in a 50-year period", Surgery vol. 112, pp. 1139-1147, 1992.

[20] Rodriguez JM, Moreno A, Paririla P, "Papillary thyroid microcarcinoma: clinical study and prognosis", Eur J Surg vol. 163 , pp. 255-259, 1997.

[21] Lin KD, Lin JD, Huang MJ, "Clinical presentations and predictive variables of thyroid microcarcinoma with distant metastasis", Int Surg, vol. 82, pp. 378-381, 1997.

[22] Rassael H, Thompson LDR, Heffess CS, “A rationale for conservative management of microscopic papillary carcinoma of the thyroid gland: a clinic-pathological correlation of 90 cases" Eur Arch Otorhinolaryngol, vol. 255, pp. 462-467, 1998.

[23] Sugitani I, Fujimoto Y, "Symptomatic versus asymptomatic papillary thyroid microcarcinoma: A retrospective analysis of surgical outcome and prognostic factors", Endocrine J, vol. 46, pp. 209-216, 1999.

[24] Falvo L, D’Ercole C, Sorrenti S, "Papillary micro carcinoma of the thyroid gland: Analysis of prognostic factors including histological subtype", Eur J Surg, vol. 588, pp. 28-32, 2003.

[25] Wada N, Duh QY, Sugino K, "Lymph node metastasis from 259 papillary thyroid microcarcinomas: frequency, pattern of occurrence and recurrence, and optimal strategy for neck dissection”, Ann Surg, vol. 237, pp. 399-407, 2003.

[26] Chow SM, Law SC, Chan JK, "Papillary microcarcinoma of the thyroid: prognostic significance of lymph node metastasis and multifocality", Cancer vol. 98, pp. 31-40, 2003.

[27] Ito Y, Tomoda C, Uruno T, "Papillary microcarcinoma of the thyroid: how should it be treated?", World J Surg vol. 28, pp. $1115-1121,2003$

[28] Sobin LH and Wittekind $\mathrm{CH}$, Editor. UICC: TNM classification of malignant tumors, edn 6. New York, NY: Wiley-Liss; 2002.

[29] Shimamoto K, Satake H, Sawaki A, "Preoperative staging of thyroid papillary carcinoma with ultrasonography”, Eur J Radiol, vol. 29(8), pp. 4-10, 1998.

[30] Tomada C, Uruno T, TakamuraY, "Ultrasonography as a method of screening for tracheal invasion by papillary thyroid cancer", Surg Today, vol. 35(10), pp. 819-22, 2005.

[31] Yamamura N, Fukushima S, Nakao K, "Relation between ultrasonographic and histologic findings of tracheal invasion by differentiated thyroid cancer", World J Surg, vol. 26(8), pp 1071-3, 2002.

[32] Yamashita H, Noguchi S, Murakami N, "Extracapsular invasion of lymph node metastasis is an indicator of distant metastasis and poor prognosis in patients with thyroid papillary carcinoma", Cancer, vol.80(12), pp. 2268-72, 1997.

[33] Miralliè EE, Guillan TT, Bridji BB, "Therapeutic impact of $\mathrm{DG}-\mathrm{PET} / \mathrm{CT}$ in the management of iodine-negative recurrence of differentiated thyroid carcinoma", Surgery vol. 142(6), pp. 952-8, 2007.

[34] Patel KN, Shaha AR, "Locally advanced thyroid cancer", Curr Opin Otolaryngol Head Neck Surg, vol. 13, pp. 112-116, 2005.

[35] Honings J, Stephen AE, Marres HA, "The management of thyroid carcinoma invading the larynx or trachea", The Laryngoscope, vol. 120, pp. 682-689, 2010.

[36] Park CS, Suh KW, Min JS, "Cartilage-shaving procedure for the control of tracheal cartilage invasion by thyroid carcinoma", Head Neck, vol. 15, pp. 289-291, 1993.

[37] Nishida T, Nakao K, Hamaji M, "Differentiated thyroid 
carcinoma with airway invasion: indication for tracheal resection based on the extent of cancer invasion", $J$ Thorac Cardiovasc Surg, vol. 114, pp. 84-92, 1997.

[38] Britto E, Shah S, Parikh DM, "Laryngotracheal invasion by well-differentiated thyroid cancer: diagnosis and management”, J Surg Oncol, vol. 44, pp. 25-31, 1990.

[39] Frazell EL, Foote FW, "Papillary cancer of the thyroid; a review of 25 years of experience", Cancer, vol. 11, pp. $895-922,1958$

[40] Melliere DJ, Ben Yahia NE, Becquemin JP, "Thyroid carcinoma wuth tracheal or esophageal involvement: limited or maximal surgery?", Surgery, vol. 113, pp. 166-172, 1993.

[41] Clark RL, Ibanez ML, White EC, "What constitutes an adequate operation for carcinoma of the thyroid?" Arch Surg, vol. 92 , pp. 23-26, 1996

[42] McConahey WM, Hay ID, Woolner LB, "Papillary thyroid cancer treated at the Mayo Clinic, 1946 through 1970: initial manifestations, pathologic findings, therapy, and outcome", Mayo Clin Proc vol. 61, pp. 978-996, 1986.

[43] Lawson VG, "The management of airway involvement in thyroid tumors", Arch Otolaryngol vol. 109, pp. 86-90, 1983.

[44] $\mathrm{Hu} \mathrm{A}$, Clark J, Payne RJ, "Extrathyroidal extension in well-differentiated thyroid cancer: macroscopic vs microscopic as a predictor of outcome", Arch Otolaryngol Head Neck Surg, vol. 133, pp. 644-649, 2007.

[45] Schindel J, "Surgery in malignant tumors of the thyroid gland. A review of 15 years' experience with 225 cases", Ann Otol Rhinol Laryngol, vol. 80, pp. 61-66, 1971.

[46] Breaux GP, Guillamondegui OM, "Treatment of locally invasive carcinoma of the thyroid: how radical?", Am J Surg, vol. 140 , pp. 514-517, 1980.

[47] Segal K, Abraham A, Levy R, "Carcinomas of the thyroid gland invading larynx and trachea", Clin Otolaryngol Allied Sci, vol. 9, pp. 21-25, 1984

[48] Tsumori T, Nakao K, Miyata M, "Clinicopathologic study of thyroid carcinoma infiltrating the trachea", Cancer, vol. 56, pp. 2843-2848, 1985.

[49] McCarty TM, Kuhn JA, Williams WL, "Surgical management of thyroid cancer invading the airway", Ann Surg Oncol, vol. 4, pp. 403-408, 1997.

[50] Koike E, Yamashita H, Noguchi S, "Bronchoscopic diagnosis of thyroid cancer with laryngotracheal invasion", Arch Surg, vol. 136, pp. 1185-1189, 2001.

[51] Sywak M, Pasieka JL, McFadden S, "Functional results and quality of life after tracheal resection for locally invasive thyroid cancer", Am J Surg, vol. 185, pp. 465-467, 2003.

[52] Tsai YF, Tseng YL, Wu MH, "Aggressive resection of the airway invaded by thyroid carcinoma", Br J Surg, vol. 92, pp. 1382-1387, 2005.

[53] Randolph GW, Kamani D, "The importance of preoperative laryngoscopy in patients undergoing thyroidectomy: voice, vocal cord function, and the preoperative detection of invasive thyroid malignancy", Surgery, vol. 139, pp. 357-362, 2006.

[54] Friedman M, Skolnik EM, Berlinger FG, "Laryngotracheal invasion by thyroid-carcinoma”, Ann Otol Rhinol Laryngol, vol. 91, pp. 363-369, 1982.

[55] Ballantyne AJ, "Resections of the upper aerodigestive tract for locally invasive thyroid cancer", Am J Surg, vol. 168, pp. 636-639, 1994.

[56] Segal K, Shpitzer T, Hazan A, "Invasive well-differentiated thyroid cancinoma: effect of treatment modalities on outcome", Otolaryngol Head Neck Surg, vol. 134, pp. 819-822, 2006

[57] McCaffrey TV, Bergstralh EJ, Hay ID, "Locally invasive papillary thyroid carcinoma: 1940-1990", Head Neck, vol. 16(2), pp. 165-72, 1994.

[58] Donnelly MJ, Timon CL, McShane DP, "The role of total laryngectomy in the management of intraluminal upper airway invasion by well-differentiated thyroid carcinoma", Ear Nose Throat J, vol. 73, pp. 659-662, 1994.

[59] Friedman M, Danielzadeh JA, Caldarelli DD, "Treatment of patients with carcinoma of the thyroid invading the airway", Arch Otolaryngol Head Neck Surg, vol. 120(12), pp. 1377-81, 1994.

[60] Talpos GB, "Tracheal and laryngeal resections for differentiated thyroid cancer", Am Surg, vol. 65(8), pp. 754-9, 1999.

[61] Breaux GP, Guillamondegui OM, "Treatment of locally invasive carcinoma of the thyroid: how radical?", Am J Surg, vol. 140(4), pp. 514-7, 1980.

[62] Donnelly MJ, Timon CI, McShane DP, "The role of total laryngectomy in the management of intraluminal upper airway invasion by well-differentiated thyroid carcinoma", Ear Nose Throat J, vol. 73(9), pp. 659-62, 1994.

[63] Kim KH, Sung MW, Chang KH, "Therapeutic dilemmas in the management of thyroid cancer with laryngotracheal involvement", Otolaryngol Head Neck Surg, vol. 122(5), pp. 763-7, 2000.

[64] Segal K, Abraham A, Levy R, "Carcinomas of the thyroid gland invading larynx and trachea", Clin Otolaryngol Allied Sci, vol. 9(1), pp. 21-5, 1984.

[65] Ballantyne AJ, "Resections of the upper aerodigestive tract for locally invasive thyroid cancer", Am J Surg, vol. 168(6), pp. 636-9, 1994.

[66] McCaffrey TV, Lipton RJ, "Thyroid carcinoma invading the upper aerodigestive system”, Laryngoscope, vol. 100(8), pp. 824-30, 1990.

[67] Sugenoya A, Asanuma K, Shingu K, "Clinical evaluation of upper mediastinal dissection for differentiated thyroid carcinoma”, Surgery, vol. 113, pp. 541-544, 1993.

[68] Ito Y, Tomoda C, Uruno T, "Clinical significance of metastasis to the central compartment from papillary microcarinoma of the thyroid", World J Surg, vol. 30, pp. 91-99, 2006.

[69] ItoY, Miyauchi A, "Lateral and mediastinal lymph node dissection in differentiated thyroid carcinoma: indications, benefits, and risks", World J Surg, vol. 31, pp. 905-915, 2007.

[70] Dralle H, Gimm O, "Lymphadenektomie beim schilddrusencarcinom” Chirurg, vol. 67, pp. 788-806, 1996. 
[71] Martenson H, Terins J, "Recurrent laryngeal nerve palsy in thyroid gland surgery related to operations and nerves at risk", Arch Surg, vol. 120, pp. 475-482, 1985.

[72] Scheumann GF, Seeliger H, Musholt TF, "Completion thyroidectomy in 131 patients with differentiated thyroid carcinoma", Eur J Surg, vol. 162, pp. 677-689, 1996

[73] McConahey WM, Hay ID, Woolner LB, "Papillary thyroid cancer treated at Mayo Clinical, 1946 through 1970: initial manifestations, pathologic findings, therapy and outcome", Mayo Clin Proc, vol. 61, pp. 978- 996, 1986.

[74] Wanebo HJ, Adrews W, Kaiser DL, "Thyroid cancer: Some basic considerations", Am J Surg, vol. 142, pp. 474-479, 1981.

[75] Candy B, "Surgery of thyroid cancer", World J Surg, vol. 5, pp. 3-14.

[76] Simon D, Goretzki PE, Witte J, "Incidence of regional recurrence guiding radicality in differentiated thyroid carcinoma", World J Surg, vol. 20, pp. 860-866, 1996.
[77] Marchesi M, Biffoni M, Biancan F, "Predictors of outcome for patients with differentiated and aggressive thyroid carcinoma”, Eur J Surg, vol. 558, pp. 46-50, 2002.

[78] Machens A, Hinze R, Thomusch O, "Pattern of nodal metastasis for primary and reoperative thyroid cancer", World J Surg, vol. 26, pp. 22-28, 2002.

[79] Karam M, Gianoukakis A, Feustel PJ, "Influence of diagnostic and therapeutic does on thyroid remnant ablation rates", Nucl Med Commun, vol. 24, pp. 489-495, 2003.

[80] Kebebew E, Clark OH, "Differentiated thyroid cancer: "complete" rational approach", World J Surg, vol. 24, pp. 942-951, 2000.

[81] Mazzaferri EL, Jhiang SM, "Long-term impact of initial surgical and medical therapy on papillary and follicular thyroid cancer", Am J Med, vol. 97, pp. 418-428, 1994. 